Voces

\section{Patrimonio, ¿necesidad vital?}

\section{Armando Nougués}

Médico naturista. Centro de Medicina Integral ${ }^{1}$

He dedicado profesionalmente los últimos veinticinco años de mi vida a cuidar la salud de las personas desde un punto de vista integral, es decir, no solamente en lo referente a lo corporal sino también a lo psicológico y lo espiritual. A poco observador que haya sido durante todo este tiempo, considero que he tenido suficiente campo de experiencia como para aprender y seguir aprendiendo acerca de lo que cada uno de nosotros siente como necesidad así como sobre la frustración que se experimenta cuando dichas necesidades vitales, por la razón que fuere, no se ven cubiertas.

Para abordar un asunto como el que aquí se plantea, el patrimonio cultural como necesidad vital, necesito primero sentar unas bases fundamentales para que la tesis que propongo y defiendo pueda ser mínimamente comprendida (aunque no necesariamente compartida). Lo primero que he de plantear es ¿de qué modelo de ser humano estamos hablando? Puesto que partir de concepciones muy diferentes de lo que un ser humano es nos llevaría a defender postulados y conclusiones posiblemente distintas, debido a que si manejamos paradigmas desiguales con puntos de partidas implícitos diferentes nuestros razonamientos divergirian inevitablemente hasta el infinito sin que lográsemos el más mínimo acuerdo. Así que me permitiré exponer mi modelo respecto a la concepción antropológica de la forma más abreviada posible, no para sentar ningún tipo de dogma, sino más bien para facilitar al lector la comprensión de todo lo que a continuación se deriva así como las conclusiones a las que basándome en eso puedo llegar a establecer.

Es claro y evidente que cada uno de nosotros está constituido por una dimensión biológica, orgánica y material, que es nuestra corporalidad. Además, posee una dimensión psíquica en la cual se generan nuestros pensamientos, sentimientos y voliciones. Todo ello animado por la energía sin la cual ni nuestros músculos se moverian ni nuestros órganos funcionarian. El gradiente energético cero solamente se da en el cadáver. Hasta aquí podemos estar todos de acuerdo porque todo lo dicho parece una obviedad. Pero ¿qué podría afirmarse respecto a la dimensión espiritual del ser?

Para cualquier buen materialista la cosa está clara. Simplemente no existe, son paparruchas e invenciones de curas y monjas. Y puede que en algo lleve razón. Es posible que no exista de la forma que nos han contado. Pero dejemos esto en suspenso manteniendo, por supuesto, el respeto a todas las creencias.

No obstante, incluso el más materialista de los sujetos convendrá conmigo que el ser humano posee "algo" que le hace diferente del resto de los mamíferos. Es como una especie de "soplo divino", una cualidad especial, quizás más fácil de experimentar que de definir. Ese "algo" es lo que hace posible que alguien se pueda deleitar e incluso extasiar escuchando a Falla, admirando un cuadro de Picasso o, tal vez, elevarse hacia lo sublime bajo el influjo embriagador de los olores a mirto y azahar mientras pasea por los recónditos rincones de la Alhambra escuchando el sonido musical de sus fuentes cantarinas. No me cabe duda que cualquier persona con cierta sensibilidad podría apreciar todo lo anterior, por muy materialista que fuese.

Pero eso es la mente, podría argumentar, eso no es el espíritu, podria decirme. Sí, pero no es cualquier nivel de la mente sino que más bien es una dimensión sutil de la misma. La mente burda o grosera, como la denominan los tibetanos, corresponde a lo que el profesor Rojo Sierra, catedrático emérito de Psiquiatría de la Universidad de Valencia, denominó en su día como Zooconsciencia o Consciencia Basal. Un tipo de consciencia ésta que compartimos con los animales, como por ejemplo la capacidad de darse cuenta de que se tiene hambre o que se tiene sed o que hay un peligro. Pero "el darse cuenta de que te das cuenta" es un aspecto de la consciencia especificamente humana, y que evolutivamente se ha desarrollado hasta lo que el profesor Rojo denominó Autoconsciencia tipo II - Consciencia de la Trascendencia (otra palabra mal interpretada en estos tiempos).

Trascender significa ir más allá de lo aparente, traspasar una cuestión de cierto ámbito limitado. Así cuando en lugar de ruidos somos capaces de escuchar música, y en lugar de ver borrones de colores somos capaces de admirar la belleza y el mensaje oculto que hay en un cuadro, o cuando en lugar de montones de piedras o ruinas en medio del campo percibimos la grandiosidad de una civilización y el talento de sus constructores, estamos trascendiendo la realidad material y realizando una función psíquica propia de la Autoconsciencia tipo II, que bien podríamos convenir en llamar consciencia espiritual.

Es posible que la dificultad respecto a la palabra espíritu resida en ponerse de acuerdo de si es preexistente o no, si es mortal o no y si habitará en un futuro paraíso o no. Pero esa discusión de momento podemos dejarla aplazada ya que nos desviaría de lo que estamos tratando y nos enzarzaría en defender o atacar cuestiones que entran dentro del ámbito de las creencias personales, las cuales, considero nuevamente, hemos de respetar.

En el lenguaje coloquial solemos utilizar expresiones como "espíritu culto", "espiritu elevado", "espíritu sensible" para hacer referencia a quienes son capaces de apreciar lo refinado de cada fenómeno. Considero que podríamos estar de acuerdo en llamar espíritu a esa función sutil de la mente que nos permite trascender lo aparente y conectar con los aspectos más elevados de cada ser humano, sin menoscabo de que para otras personas tenga además otros atributos. Trato con esto de lograr, respecto al término espíritu, un consenso en el que podríamos coincidir sin grandes contradicciones. 


\begin{tabular}{|l|}
\hline Voces \\
Patrimonio, ¿necesidad \\
vital? \\
Armando Nougués \\
\hline
\end{tabular}

Así que, una vez dicho esto, puedo plantear lo siguiente. Hoy día todos somos conscientes de la importancia de una correcta alimentación para el mantenimiento de la salud de nuestro cuerpo, pero ¿cómo nutrimos la psique? ¿Cómo nutrimos nuestra dimensión energética? ¿Cómo nutrimos nuestro aspecto espiritual? Si somos seres globales que funcionamos sistémicamente, necesitaremos aportar una correcta nutrición a los distintos elementos de los que estamos constituidos. Sabemos que aquello que está mal nutrido es incapaz de florecer y dar frutos. Luego icómo hemos de nutrirnos para lograr, como seres humanos, dar nuestros mejores frutos?

Nacemos como mamíferos pertenecientes al género y especie Homo sapiens sapiens. A lo largo de nuestro proceso de desarrollo hemos de trascender la dimensión estrictamente biológica de la vida para proyectarnos a la dimensión especifica del ser que inaugura una existencia plenamente humana. Nos humanizamos gracias al contacto con los demás seres y a la interacción que establecemos dentro del contexto cultural concreto en el que nos ubicamos. Es por ello que, en cierto modo, debiéramos sentirnos como auténticos hijos de nuestro patrimonio cultural, evidentemente no en el sentido puramente biológico sino, sobre todo, en el psicológico y en el espiritual.

Una apropiada nutrición integral del ser humano referida a su momento presente, así como el tipo de conexión que establecemos a través de la cultura y el patrimonio con nuestra memoria colectiva como grupo, nos permiten establecer y completar los importantes procesos internos de identificación y pertenencia de los que dependen en buena medida nuestro bienestar.

La psicología nos enseña que la satisfacción de una necesidad va acompañada de placer. Esto que es muy evidente para las necesidades de tipo material (comer, beber, etc.), con frecuencia no parece tan claro cuando nos referimos a necesidades de ámbito superior. Sobre todo porque a veces tenemos dificultad para entenderlas como verdaderas necesidades. Por tanto podríamos preguntarnos ies la cultura una necesidad o simplemente algo creado por aquellos que no tienen que preocuparse por qué han de comer o qué han de vestir? ¿Tiene algo que ver el patrimonio, entendiéndolo como un bien cultural colectivo, en el proceso personal de desarrollo e individuación del sujeto? ¿Puede existir un ser humano en ausencia de una cultural humanizante o desarraigado de su patrimonio, considerándolo ahora como parte de la memoria colectiva del grupo al que se pertenece?

Abraham Maslow, conocido como uno de los padres de la Psicología Humanista, nos enseña a diferenciar entre las llamadas necesidades básicas y necesidades del desarrollo. Las primeras, las básicas, incluyen no sólo las necesidades de tipo fisiológico (comer, beber, etc.) sino también aquellas otras de tipo psi- cológico, ya que éstas en caso de faltar nos harán enfermar como si padeciésemos una carencia de vitaminas o de aminoácidos. El ser humano, según los postulados de la Psicología Humanista, ha de satisfacer sus necesidades psicológicas básicas de seguridad, respeto, pertenencia y amor, y en caso de no hacerlo acabará enfermando.

Pero para un sujeto que además de procurar no enfermar pretende crecer y desarrollarse, necesitará satisfacer, además, las llamadas necesidades del desarrollo. Éstas tienen que ver con lo que se ha venido denominando como proceso de autorrealización, es decir, con el crecimiento y actualización del potencial que como seres humanos todos llevamos dentro hasta el máximo que nos sea posible.

Cuando planteo el interrogante de si el patrimonio es una necesidad vital o no, me estoy refiriendo a este último tipo de necesidades, las del desarrollo. Y esto es así porque pretendo hacer referencia a aquello que nos hace vivir plenamente como humanos y no simplemente con lo que nos permite sobrevivir como mamiferos parlantes. Desde mi punto de vista, cultura y patrimonio, en el amplio sentido de la palabra, es algo a lo que nos encontramos indisolublemente conectados psicológica y espiritualmente, tanto en el aspecto evolutivo individual como social, y sin el cual no seríamos quienes realmente somos, ni entenderíamos nuestras raíces, ni podríamos avanzar hacia donde actualmente avanzamos.

En estas líneas finales me planteo si he sabido expresar claramente aquello que pienso o si, tal vez, debido a la brevedad necesaria del texto, haya condensado en pocas líneas ciertas ideas o conceptos que requeririan una mayor extensión. Sea como fuere, y plenamente consciente de la dificultad del tema, espero haber aportado algún elemento útil para la reflexión y el debate sobre este asunto. En resumen, desde mi punto de vista, considero que el patrimonio cultural no es pues una mera creación intelectual para satisfacción de unos cuantos, más bien constituye uno de los fundamentos vitales sobre los que nos apoyamos, uno de los nutrientes imprescindibles de los que nos alimentamos y forma parte de nuestras más profundas aspiraciones individuales y colectivas, las cuales, de alguna manera, se encuentran conectadas con nuestro proceso de autorrealización. Por tanto, más allá de los vericuetos de la moda, la política o los grupos de opinión e influencia mediática, la cultura y el patrimonio podrian ser considerados como una necesidad vital de todo ser humano.

\section{Nota}

${ }^{1}$ Más información: www.centromedicinaintegral.com 